\title{
The platform economy and the precarisation of food delivery work in the COVID-19 pandemic Evidence from India
}

\author{
Sazzad Parwez and Rajiv Ranjan
}

Sazzad Parwez is an Assistant Professor in the School of Liberal Arts and Human Sciences, Auro University, Surat, Gujurat, India.

Rajiv Ranjan is a Researcher at e-Vishwavidyalaya LLP, Patna, Bihar, India.

\begin{abstract}
This study aims to explore work precarity in the platform economy from the perspective of food delivery workers. It also tries to contextualise work precarity in COVID-19 times. With the digital boom, food-based platform aggregators have emerged as a new workspace for food delivery workers in India. Food delivery workers working for platform aggregators are termed 'independent contractors' and 'delivery partners' to avoid legal issues of employer-employee relations; this enables a substantial reduction in transaction costs. Despite the huge number of food delivery workers, they are unable to organise into collectives. The platform economy is emerging as a sector offering new work opportunities, but at the same time it is plagued by low wages (and benefit), absence (or lack) of welfare measures, and digital controls contributing to the process of precarisation. The COVID-19 pandemic and resultant lockdown have aggravated the precarity of work for food delivery workers. It has led to the loss of jobs and incomes, and increased health risks, stigmas and occupation distress. Further, autonomy and flexibility should not come at the cost of the most basic social security and protection. This precarious situation calls for affirmative action from policymakers and platform aggregators.
\end{abstract}

\section{KEY WORDS}

Precarisation, platform economy, platform aggregators, food delivery workers, Covid19, India 


\section{Introduction}

This study tries to establish a conceptual and empirical relationship between the increasing precarity of work arrangements, especially in the context of the platform economy in which precarious working conditions are combined with uncertainty, and the absence of adequate statutory protection, further aggravated during the COVID-19 pandemic.

India has seen the advent of many digital enterprises in a context of technological advancement and disruption (Woodcock \& Graham, 2020). These digital platforms are catering to the needs of an increasingly affluent and growing middle class with smartphone connectivity and cheap data plans. As a result, the Indian platform economy is expected to reach $\$ 30$ billion by 2025 (NASSCOM, 2018). Even though these digital platforms have created job opportunities, they have also been associated with a number of challenges, with gig workers experiencing increasing precarity in employment.

It was against this background that, with the spread of COVID-19 across the world, India announced a nationwide lockdown from 24 March 2020, followed by phased unlocking. The spread of COVID-19 and the resultant lockdown emerged as not only a health crisis but also a humanitarian and economic disaster in India. Every sector was badly affected, and the platform economy was one of the worst affected sectors. Even though some digital platforms did benefit from the pandemic and lockdown, most were severely affected (Agrawal et al., 2015; Parwez, 2020).

The platform economy in India is marginal in terms of labour participation, and labour market institutions are largely regulated by neoliberal market policies (Sundararajan, 2016; Pant \& Shende, 2020). Central to the platform economy is so-called 'gig work', i.e. temporary and short-term work that is typically found on digital platforms that connect employers to workers (Cherry \& Antonio, 2017; Huws et al., 2017). In the platform economy, food aggregators such as Zomato ${ }^{1}$ and Swiggy ${ }^{2}$ are particularly prominent cases in India. On-demand food delivery is increasingly becoming popular, exhibiting rapid growth (with a 25-30 per cent compound annual growth rate) and estimated to become an $\$ 8$ billion market by 2022 (Boston Consulting Group, 2020). Food delivery workers managed by these platform aggregators thus represent a large gig workforce. However, due to the COVID-19 crisis, the entire food delivery workforce associated with food aggregators has faced the loss either of their entire livelihood or of a good part of their income.

In India, there is no reliable government data on gig workers. But NITI Aayog ${ }^{3}$ reckon that platform-based ride-hailing companies alone have created more than 2 million jobs (Salve \& Paliath, 2019). Across the board it has been estimated that platforms employ about 15 million workers (Tiwari et al., 2019), and about 0.44 million are associated with food aggregators (Business Today, 2019a).

1 Zomato is one of India's largest food aggregators, it started in 2008 in New Delhi to provide consumers with digital access to thousands of restaurant menus. They have more than 5,000 workers across the world. Before Covid19, Zomato used to get 19 million orders per month.

2 Swiggy is India's largest food delivery platform founded in 2014 in Bangalore. It has a delivery network focusing on logistics and locking in key resources. It has more than 218,000 workers across the board. Before Covid19, Swiggy was getting 25 million orders per month.

3 The NITI Aayog is a policy think tank of the Government of India. It was established to achieve sustainable development goals with cooperative federalism. 
The food aggregators describe their food delivery workers as 'platform partners', emphasising that they are associated with them only on a day-to-day basis. These delivery workers are treated as entrepreneurs. This strategy of treating food delivery work as an entrepreneurial venture shifts the risk and labour costs onto the workers. This encourages a perception among these gig workers that their work is an investment that will bring returns in the form of a future payoff (Leighton \& Wynn, 2011; Gandini, 2019). In practice this can be seen as a form of self-exploitation through the performance of 'hope labour' (Parwez, 2015; Mackenzie \& McKinlay, 2020).

In the context of the COVID-19 pandemic, this has had particular pernicious effects, because it has created a situation in which food delivery workers are seen as independent individuals experiencing problems due to the pandemic, absolving the food aggregators from any responsibility to provide socio-economic support. This is largely accepted, since more than 92 per cent of the Indian economy is informal in nature (National Sample Survey Office, 2012).

Further, the idea of work autonomy is important for food delivery workers, but in reality there is no autonomy. For example, workers have no say in the amount charged for delivery to customers, and there is no interaction between management and workers about matters such as wages, incentives or the nature of the work.

Loss of livelihood and income was a major issue during the COVID-19 pandemic and lockdown as food delivery workers in India largely came from weaker socioeconomic backgrounds. Many chose to leave and went back to their villages, but others, who were unable to take their bikes back to their homes which might be thousands of kilometres away, remained in the city and tried to survive with whatever little work they could find (Lalvani \& Seetharaman, 2020).

Food delivery workers are not hired with the aim of establishing a long-term employer-employee relationship. They are considered interchangeable workers (faceless workers) providing delivery services (Woodcock \& Graham, 2020). Food delivery work does not provide workers with opportunities to socialise with customers, because of time pressures, nor does it make it possible to have quality family time, because of its unpredictable nature. Food aggregators, furthermore, actively reduce interaction between workers and customers via digital management systems (Gandini, 2016).

Despite this, workers have organised to some extent, and there have been instances of strikes in various cities by workers protesting over pay cuts and dismal working conditions (Business Today, 2019b ${ }^{4}$ ). However, worker protest is reported in a negative light. Platform companies see this as misconduct.

In the traditional economy, workers can claim labour rights and social security but platform workers lack the means to organise and to influence labour market institutions (Benanav, 2019). This is reflected in an absence of pressure from the regulatory framework for platform aggregators to improve working conditions and an under-representation of food delivery workers (Stewart \& Stanford, 2017; Keune \& Pedacci, 2019). Further, the coexistence of on-demand platform work such as food

4 https://www.businesstoday.in/current/corporate/zomato-delivery-boys-executives-strike-in-mumbaibengaluru-after-food-app-cuts-incentives/story/379576.html 
delivery work with conventional jobs is blurring the divide between traditional workers and on-demand platform workers (Palier \& Thelen, 2010; Will-Zocholl, 2017).

Our study aims to deepen the understanding of precarity in platform work for food delivery workers in order to provide insight into how digitalisation shapes workers' trajectories in and out of the labour market (Palier \& Thelen, 2010; Schwander, 2018); it emphasises the prevailing institutional weaknesses in labour markets (Bohle \& Greskovits, 2012).

Drawing on our empirical research, the study explores precarity among food delivery workers, looking at their work processes and interest representation. It applies the existing conceptualisation of precarisation to the characteristics of the on-demand platform (Zomato, Swiggy, etc.) work to identify dimensions of work precarity in COVID-19 times and before in the Indian context.

It also looks at the implications of on-demand platform work in relation to the geographical, economic, social and political forms of localisation associated with food delivery work and the erosion of labour standards (Codagnone \& Martens, 2016; Will-Zocholl, 2017).

The research does not just examine the new precarious work arrangements associated with digital platforms generally but also looks specifically at changes taking place in food delivery in COVID-19 times.

The paper is structured in five sections. The first section provides an introduction to the topic and the premises underlying our research. The second section theorises the precarity of on-demand work and platforms. The third section provides a contextual analysis of work precarity on platforms in India. The fourth section provides insights drawn from our empirical evidence on the dimensions of precarity in on-demand platform work. This is followed by a final discussion and conclusion section.

\section{Research methods}

The methodology used in this study was exploratory and encompassed a literature review and the collection of field data. The study was carried out in two stages. The first stage focused on a literature review on platform work and food delivery workers to explore the dimensions of work precarity on platforms. The second stage involved empirical research, including interviews with food delivery workers.

Our attempt to understand the work precarity of platform-based food delivery work required an in-depth and interdisciplinary review of the literature. However, there is limited research on the platform economy and food delivery workers. We identified only 71 documents based on the keywords 'platform work' 'gig workers' and 'food delivery workers' from database searches on Scopus, ProQuest, Web of Science and EBSCO. This suggested that a systematic literature review was not a viable option due to the limited literature. Therefore, we adopted a more exploratory approach. To analyse the literature, we used narrative synthesis, which is a flexible method for a better critical understanding of literature.

The second stage focused on empirical evidence captured in interviews with field delivery workers. We interviewed only delivery workers associated with two major food aggregators (Zomato and Swiggy) during the COVID-19 pandemic and before. At this stage, we conducted a qualitative study of 21 food delivery workers to identify work 
precarity in food delivery work. The sampling was purposive, and some respondents were also selected based on snowball sampling, owing to limited sampling options caused by COVID-19. All interviews were face-to-face in the local language (Hindi) using semi-structured interviews and were carried out between October and November 2020; the interviews lasted between 25 and 40 minutes. Early interaction was across street intercepts in Jaipur, as all movement was highly restricted. Due to the ongoing pandemic and the nature of food delivery work we adopted a variety of different interview approaches. For example, street intercepts took place when we ordered food or a delivery man was waiting outside the restaurant.

The interviews were based on a semi-structured questionnaire designed to capture the work experiences of food delivery workers during the COVID-19 pandemic and before. Questions were focused on working conditions, mobile apps, and control, unionisation, social stigma, management apathy, health risks, lack of social security and institutional support.

Our interviews revealed that not all food delivery workers worked exclusively for a single platform. We found two workers working for both companies. We interviewed 12 delivery workers associated with Zomato and the remaining nine workers were associated with Swiggy. Eighteen workers were found to be using pedal bikes and three workers used scooters for food delivery. We were not able to locate any female food delivery worker, so all participants were male.

\section{Precarisation of work in the platform economy}

As a new form of work organisation, platform aggregators give us an opportunity to reflect on some of the ways that work is being transformed, enabling an analysis of the reconfiguration of work and related institutions and providing an insight into their impact on the precarity at work. In this study, our focus was on food delivery work as a form of 'gig work' controlled by digital platforms via the internet and smartphone (Berg et al., 2018). Platforms represent a new kind of relationship between the worker and a consumer, arranged via a digital shadow employer (Parwez, 2016a; Gandini, 2019).

Platform-based work can be categorised using a differentiation between labour and capital platforms. Three types can be identified: first, 'click-work' platforms where a worker is employed online for short-term assignments (Gandini, 2019); second, platforms that facilitate a meeting between workers and their clients for manual work (Parwez, 2015); and third, work-on-demand services, including deliveries or driving assignments made via an arrangement made and controlled by platforms aggregators (Heeks, 2017; Huws, 2014; Huws et al., 2018). Food aggregator-based delivery work falls into this third category. An additional fourth category is made up of 'capital platforms', which facilitate the renting of assets or labour, which may also cover highly precarious domestic work (Stewart \& Stanford, 2017).

Despite the small size of the platform economy, platforms bring pressure to bear on regulatory bodies, because their business models have serious implications for working conditions and labour market institutions, with a likelihood that online platform work will impact industrial relations and employment standards.

There is no universally accepted definition of work precarity in relation to platforms (International Labour Organization, 2016). Aust and Holst (2006: 291-313) 
suggest that it should be contrasted with standard employment, defined as 'a relationship having socially secured, long-term, and full-time employment with a wage that allows for a decent living. The International Labour Organization (2016: 396) defined non-standard forms of employment as 'temporary work, part-time work, temporary agency work and other multi-party employment arrangements, disguised employment relationships, and dependent self-employment'. We follow this approach in considering non-standard employment as a category that includes temporary, fixedterm, part-time, and self-employment (Parwez, 2016a). Kalleberg (2018) looks at the characteristics of precarious employment, seeing it as comprised of uncertainty and unpredictability, and risky from the worker's perspective. Dörre (2005) places work precarity in the context of the material, social communication and institutional dimensions or 'spheres' of work, which can be plotted in relation to on-demand platform work. The material sphere captures job insecurity and lack of economic dignity in the job. Precarity in the context of social communication focuses on the lack of social networks at the workplace. The institutional sphere refers to exclusion from certain social rights. Adopting this framework makes it possible to analyse the multidimensional structure of precarity in platform work.

Workers for platform aggregators further suffer from fragmented and irregular work schedules (Drahokoupil \& Piasna, 2019). The irregularity and fragmentation result from the on-demand character of platform services. However, this work precarity is aggravated by a lack of social security, recognition, health and safety issues, workload, absence of collective actions, occupational stress, and low and unpredictable earnings (Fidler, 2016; Parwez, 2016b).

Digital enterprises like Zomato and Swiggy have created excitement among investors, consumers and policymakers in India. Their business model, based on the transportation of customers and products, is achieved by a contractual arrangement with a fleet of cyclists to deliver food to the respective customers. To be employed by food aggregators an individual only requires a bike and smartphone. This may sound simple and convenient, but there is evidence of detrimental impacts on workers (Aloisi, 2016).

Work precarity does not only concern the contractual arrangements but also derives from less visible aspects of working conditions. Sometimes in a traditional employer-employee relationship dismal working conditions can lead to work precarity with aggravation of work pressure and occupational stress (Stewart \& Stanford, 2017). But work precarity on platforms is largely hidden, with entrenched distinct forms of control using feedback, ranking and rating systems (Gandini, 2019). Further, precarity at work is characterised by non-standard or temporary employment with low wages, insecurity, no protection, and inability to support the household.

In India, food delivery workers associated with digital platforms are not regulated by labour law and the work arrangements between platform and workers do not fall into the traditional employer-employee relationship. This is because these platforms aggregators do not recognise food delivery workers as employees, rather terming them as 'delivery partners'. This allows companies to avoid compliance with labour laws and reduces the labour cost. For example, companies do not need to pay wages, as food delivery workers are partners; they are only paid delivery charges and incentives. Food delivery workers need to be flexible to respond to consumer 
demand, but are tightly supervised by the platforms, raising the question of whether they can be regarded as genuinely autonomous, which is also a symptom of work precarity (Leighton \& Wynn, 2011; Parwez, 2015; Gandini, 2019).

\section{Work precarity and platform work in India}

In India, with the rapid expansion of the service sector in urban and semi-urban areas, a variety of different forms of informal work opportunities have emerged. Accompanied by cheaper access to technology and internet services, this has facilitated the rise of platform enterprises, including food aggregators such as Zomato and Swiggy. Work arrangements in these platforms tend to be informal and limited to a form of partnership in which platforms call the shots. The forms of employment provided by such platforms are temporary, and low paid, providing tightly-controlled on-demand work that lacks protection. The workforce includes those who engage in such activity on a regular or occasional basis, for primary or supplementary earnings.

The scale at which work and working conditions remain informal in India is gargantuan. About 93 per cent of all Indian households depend on informal work for their household income (National Sample Survey Office, 2012). Informal work arrangements ensure the absence of a safety net, including a lack of pensions, health insurance and other benefits, making individuals and their households vulnerable to the vagaries of daily life and at the mercy of the employer. For example, the absence of health insurance alone is the cause of pushing 12 million households every year below the poverty line, i.e. approximately 60 million people across the total population, into the web of absolute poverty (Keane \& Thakur, 2018). Further, 92 per cent of the 61 million jobs created post-liberalisation (1991) also happened to be informal jobs (Periodic Labour Force Survey by the National Sample Survey Organization, 2017-2018), indicating the extremely precarious work environment prevailing in the Indian labour market.

Digital technologies are changing the very nature of work while facilitating the rise of the platform economy. This has facilitated the creation of new work opportunities while aggravating precariousness for gig workers (Kenney \& Zysman, 2016). The precarisation of work on platforms increases workers' vulnerability and makes collective actions and unionisation difficult (Sundararajan, 2016). This creates a situation where the workers lack bargaining power, even though the value they create for the platforms is considerable.

As well as being detrimental for individual workers, this also has broader implications for socio-economic inequality. Structural institutional asymmetries benefit the organisations that control capital and technology while leaving those who are at the bottom of the economic pyramid (e.g. food delivery workers) neither appropriately compensated nor with the ability to change their societal condition (Parwez, 2016a; Codagnone \& Martens, 2016). Such a condition leads to the entrenchment of the inequalities that modernisation and technological innovation are supposed to address.

It is important to emphasise that the ways in which platforms use technology to control labour play a major role in exacerbating the features of precarity that are detrimental to worker's conditions. Labour market institutions tend to facilitate such a change, leading to market failure. As a result, when work, which is one of the primary 
sources of societal transformation, becomes non-standard, there are broader social implications (Stewart \& Stanford, 2017; Pant \& Shende, 2020). The prevailing practices of platforms thus raise serious general questions.

\section{Research findings}

We now turn to the results of our empirical research among workers for Zomato and Swiggy, two prominent examples of platforms in the food delivery sector. These food aggregators have hired thousands of food delivery workers on 'gig' contractual work arrangements that are supervised and controlled online (Veen et al., 2020).

Our focus was on the ways in which the COVID-19 pandemic crisis aggravated the misery of food delivery workers, forced to continue working in the absence of social security protection, despite the critical risks.

The severity of their situation can be illustrated by the case of Participant 11, a 28-year-old with secondary school education, who reported that in a fatal accident on duty he fractured his arm. His field manager did not respond to the calls and he was forced to pay for his medical expenses himself. The accident left him seriously injured and unable to work for many months. Later he tried to claim medical insurance, but there was no relief, even after many attempts.

Food delivery workers are essential to the proper functioning of food delivery platforms such as Zomato and Swiggy. They are the primary risk bearers in the service delivery cycle. They are always short of time, and constrained by pressures to work fast, to take undue risks, sometimes leading to road accidents. In principle, this should entitle them to appropriate compensation, and protection mechanisms should be in place as a necessary condition of platform-based work arrangement, enforced via regulations and laws (De Stefano, 2016; Stewart \& Stanford, 2017). These protections were not, however, in place among the workers we interviewed.

Another issue is data (sometimes described as 'the new oil') giving a higher bargaining power to the platforms that own it. They, by design, capture and possess data on all stakeholders: customers and food delivery workers (Arntz et al., 2016). In relation to customers, these data are mainly used to attract more orders, but in the case of food delivery workers are used in connection with control and management and hence to strengthen the power of platforms over workers (Romei, 2015). By avoiding the status of employers, platforms can keep costly welfare activity at bay and work towards efficiency and profit.

Furthermore, with the COVID-19 pandemic and nationwide lockdown causing the loss of millions of jobs in India, especially at the bottom of the pyramid, these forms of management aggravate the precarious situation of food delivery workers who are already struggling with dismal working conditions. Such a devaluation of labour seems unsurmountable in the absence of collective actions and suitable labour laws (Stewart et al., 2020).

An arrangement whereby food delivery workers are treated as 'partners' allows platforms to avoid legalities. It also facilitates the avoidance of an employment contract, terms of duty, benefits, notice periods and rights (Parwez, 2015). Platforms claim that a work arrangement of this kind provides autonomy and flexibility to workers, but, contrary to this, the control exercised in terms of allocation of orders, constant 
monitoring, the structure of delivery charges, incentives and penalties suggests a contrary situation. The food delivery workers we interviewed considered themselves to be employees who deserved decent working conditions.

The platform enterprises for whom they work seem to be repackaging and normalising a non-standard work environment under cover of terms such as autonomy and flexibility. This is in line with the finding of the International Labour Organization (2018) that there is no universally accepted definition of gig work or platform-based ride/delivery work.

As Goods, Veen and Barratt (2017) point out, precariousness and exploitative practices are part of the reality of work in the platform economy. However, their consequences go beyond this immediate context. This development and the dynamism in the labour market associated with it have more general implications for the 'future of work and society' (Alamyar, 2017). They contribute to furthering the process of precarisation for all labour. Lack of institutional intervention has shifted the nature of the labour market towards the idea of flexible, part-time and temporary employment (De Groen et al., 2016). This contributes to a validation of this new form of work, characterised by low wages, insecurity, absence of social security and barriers to collective actions (Rubery et al., 2018). It thus exacerbates systematic precariousness.

Another respondent, Participant 6, illustrates how workers are drawn into the precarious food delivery workforce. A 24-year-old college graduate; he had been working for Swiggy for four months. Before this, he was running a fruit-and-vegetable shop. But his business ran up huge losses, and he was forced to work as a food delivery worker. He aspired to earn enough money to cover his losses and restart the business with more capital and market experience.

He illustrated a common pattern whereby platform work appeared to represent a kind of short-term or freelance work that might fit with an entrepreneurial career trajectory, holding out a promise of autonomy and upward mobility. This was reflected in the demographic profile of the food delivery workers we interviewed, all of whom were male and young. This also conforms with some societal stereotypes, in which all such workers are assumed to be male and young. They came from very diverse socio-economic backgrounds, in contrast with most other industries in India. In many cases, graduates and postgraduates were combining working as food delivery workers with their studies. Their working conditions reinforced the informality of the work, which may be relatively better than traditional informal work in rural and urban India. However, the reality of the work, with its low pay and long hours, often belied the promise that had attracted them into the work in the first place.

In many cases, our interviewees did not see delivery work as a permanent occupation but, rather, a staging post in their careers. Participant 3 was only 18 years old, with secondary education. He worked for Zomato as a food delivery worker to supplement his family's income. Every day he worked for 12 hours. He said that he had been attracted to the work by the flexibility in working hours and being able to commute on his bike. He was looking for a government job.

Such attitudes often lead to downplaying or ignoring the risks involved in delivery work.

Driving in the highly crowded roads of Indian cities, with the pressure of delivering the food quickly, creates major risks of accidents. This is one of several forms of 
hardship that form part of the food delivery job in India, especially in the extreme weather conditions in the cities. Food delivery within the required time is a must; failure to do so may result in a detrimental rating against their names in the digital management system. The use of digital technologies to supervise and extract surplus labour value is revealed to be directly related to punishment and reward systems which have negative human consequences, uncovering a dystopian reality.

Some food aggregators list medical insurance as one of the benefits of work for them, suggesting that they acknowledge the presence of physical risks. However, workers are largely unaware of the modalities of insurance (Donovan et al., 2016).

Participation in the food delivery labour market requires ownership of a bike and a smartphone. This restricts access, excluding workers who do not own or cannot acquire them. Often, individuals wanting to take up this form of work are forced to take out a loan, using informal means, access to which is dependent on existing social networks. Combined with the fact that the nature of the work requires a food delivery worker to be on-road at odd hours for a long duration, and societal norms concerning safety, this is one of the factors that restricts the entry of women into the field.

These factors combine with others to entrench the precarity of platform-based food delivery work and establish poor working conditions as a norm. One of these is the very long working hours, averaging 12 hours per day - well above the ILO standard. This is in turn linked to the wage payment system, which is based on piece-rates and incentive payments. This incentive-based system pushes workers to work longer hours. Their income is made up of a combination of delivery charges per order and minimal incentives earned over and above these.

There is a direct contradiction between the supposed flexibility to work according to convenience and the compulsion to keep the app open. This questions the idea of autonomy and flexibility promised by the companies, which are directly contrary to the daily experiences of workers. The resulting discontent and stress was expressed by several of our interviewees. As one put it:

I want an office job, so, I don't have to run all day long. I want to leave this job as this can't be a lifelong job but there are no other options. (Participant 1: a 29-year-old commerce graduate who had worked for Swiggy for almost a year)

In the prevailing conditions, it is difficult to consider this form of work as a lifelong source of earnings, with participation in the digital labour market appearing to be transient for most workers. This unsustainability gives platform work the peculiar characteristic of being a field in which high job creation is coupled with high labour turnover. This suggests that the increasing precarity of work and the constant exploitation of the workers need to be addressed by affirmative actions aimed at digital enterprises.

\section{Food delivery workers in COVID-19 times}

COVID-19 and the nationwide lockdown have exposed the precarity of work in many sectors of India's labour market, but particularly in food delivery. With inadequate employment rights and insufficient social protection, the pandemic has threatened and destroyed the livelihoods and incomes of thousands of food delivery workers. It has put 
the spotlight on the need and struggle of gig workers for appropriate social security and compensation.

\section{The first lockdown}

Participant 4, a 20-year-old with primary education who had been working with Zomato for seven months, told us:

During lockdown there was no roadside (affordable) food to eat. Luckily, there were two restaurants providing food to people like us.

The pandemic and resultant lockdown massively affected food delivery work, making it all too visible that, even though platform aggregators claim to be technological enterprises, their services are highly labour-intensive, meaning that labour costs are paramount. Their first reaction to the crisis was therefore to cut corners by retrenching workers. Zomato cut 13 per cent of its workforce and enforced a pay cut for the remaining food delivery workers. This was followed by a similar move from Swiggy, which cut about 1,000 jobs. The move was to reduce costs (Indian Express, 2020).

The effects of this were described to us by Participant 9, a 28-year-old college graduate who had been working for Zomato for two years.

Most of Zomato officials are working from home, there is no customer-care option for any kind of problem. I am also worried about losing this job or getting a new rate card for delivery. I don't have enough savings to last even a month.

The pandemic forced food aggregators to lay off thousands of workers, most of whom were the sole breadwinners of their families (Sowmiya, 2020). The fear that they might become victims of this job loss has forced food delivery workers to work even harder, despite the demanding realities, compelling them to keep on waiting for the next order to earn something, at any cost and risk. This was illustrated by Participant 18, a 25-year-old diploma holder, who had worked for Zomato for nine months.

These days I am getting very few orders to deliver even though lockdown is eased. I am still working 10 hours, but the company is neither concerned nor providing any incentive.

Loss of livelihood and income was also affected by a decline in consumer demand, also driven by fear. Even after lockdown was eased after the first wave of the pandemic, a new pattern of normal consumer behaviour seemed to have emerged. Participant 12, a 21-year-old college dropout, who had been working for Swiggy for six months, described the uncertainty that resulted.

Somehow I am managing without any work but don't know what will happen next month onwards. I am under pressure to pay for rent and loans.

Similarly, Participant 20, a 24-year-old postgraduate who had worked for Swiggy for ten months said:

I am not getting enough orders to get a reasonable incentive, for this I invested extra 2 hours, but all went in vain. 
This was echoed by Participant 5, a 32-year-old college dropout, who had worked for Zomato for one year, who reported:

I am not able to complete my daily target as there are not enough orders. Every day I start delivery of food from 8 in the morning to till 11 in the night to complete my target, so I remain employed with the company even though I am making very little in this difficult time.

Loss of income was coupled with exposure to the risk of infection with the highly contagious coronavirus (Lalvani \& Seetharaman, 2020). Even though platforms rely heavily on gig workers, their actions suggest little regard for their safety. Food aggregators lacked strategies for workers' safety from COVID-19. There were a few cases where masks were distributed and a standard health insurance scheme was mentioned, but most workers were forced to purchase their own masks and sanitiser. And insurance coverage did little to gain workers' confidence, given their past experiences with lack of accident cover.

Delivery workers were, overwhelmingly, having to take responsibility for their own protection, and that of their families, during the pandemic. This often led to expense and discomfort. Participant 17, a 20 -year-old with only secondary education, had been working for Zomato for the last 11 months. He had two young children and elderly parents. He told us

It's really hot in summer but I only wear the company's uniform over my clothes as an extra layer, so, whenever I come back home, I will shed the uniform outside.

Then I go to the bathroom to change my clothes, wash my face and hands before interacting with the family.

Platforms claimed that they supplied masks and sanitisers, but reports and field evidence suggested a different story. Participant 2, a 27-year-old school dropout who had worked for Swiggy for four months, informed us

Since lockdown is enforced, we are forced to bear the expense of mask and sanitiser. Manager says we shall be getting them soon but for many weeks it went like this. We also never received any reimbursement for the expenses on mask and sanitiser.

Participant 7 was a 22-year-old college dropout. He was the only breadwinner of the family and worked as a food delivery worker due to a lack of alternative options. $\mathrm{He}$ informed us that one of his friends lost his life while delivering food. As he was driving hurriedly to deliver food on time on a rainy day, his motorcycle slipped and skidded against a live wire. He died from the electric shock. His family were unable to claim medical insurance due to their state of grief and the bureaucratic difficulty of making the claims.

The precautionary measures for the use of sanitisers, disinfectants and masks were only introduced after several reports on the subject were published and the issue was taken up by the Indian Federation of App-based Transport Workers (IFAT). Yet most food delivery workers were not aware of the health protocol and guidelines. There was, 
however. a protest by food delivery workers in Hyderabad over the refusal of platforms to provide safety kits, despite appeals (The News Minute, 2020). ${ }^{5}$

Participant 14 was a 24-year-old school dropout, who had worked for more than 15 months with Zomato. He drew attention to an additional source of stress for food delivery workers during the pandemic: the additional police activism associated with enforcing lockdown rules. As he put it:

This has created a fearful environment. There are blocks at every corner and police harassment is very present on a day-to-day basis.

Food delivery workers were often the victim of poor implementation of COVID-19 guidelines by the authorities. They were frequently beaten up and harassed by cops due to a lack of clarity regarding the guidelines. There were reports of physical assaults on food delivery workers by police in Bengaluru and Delhi (Lalvani \& Seetharaman, 2020). ${ }^{6}$ The use of terminology such as 'partners' for food delivery workers makes them a particularly vulnerable group, by dissociating them from the platform, and thus displacing responsibility onto them as individuals.

Participant 10, a 29-year-old with a secondary school education, had worked for Zomato for seven months. He informed us about unsafe areas where his food, phone, and cash got stolen. Once he had also been threatened with physical assault. He had tried to call the platform's field manager, but the call had been diverted to customer care, which was not helpful at all.

In this pandemic situation, food aggregators were supposed to provide contactless services, but our evidence confirmed that the companies also allowed cash transactions, diluting the rationale for contactless service and underlining the apathetic attitude of platforms and their failure to address their workers' needs and safety.

In relation to precautionary guidelines, the platforms seemed to focus more on the communication of hygienic practices to customers rather than developing and enforcing practices to protect the safety of workers and customers. Typically, they demonstrated their commitment by texting delivery workers to abide by the hygiene regulations. They also informed consumers that the platform and staff follow the WHO protocols for each delivery, with images of hygiene on the app webpage. They seemed to be more focused on image build-up than reducing the health risk.

With the recent decision by Zomato to make it mandatory for food delivery workers to use the controversial Aarogya Setu ${ }^{7}$ app, there have been further infringements of workers' autonomy and right to privacy. Nevertheless, the platforms can afford to neglect workers' autonomy because, like most players in the platform economy, they have managed to circumvent India's complex regime of labour laws, resulting in inequitable conditions exacerbating workers' already limited bargaining power (Johnston \& Land-Kazlauskas, 2018; Parwez, 2020).

5 https://www.thenewsminute.com/article/app-based-drivers-delivery-executives-protest-adequate-safety-gearbetter-income-126197

6 https://thewire.in/business/covid-19-food-delivery-workers

7 Aarogya Setu is a mobile application developed by the Government of India to reach out to and inform the users of the app regarding risks, best practices, and relevant advisories about the containment of COVID-19. 
Food delivery workers are also subject to more general social stigmatisation in Covid19 times, being harassed and discriminated against by customers, as well as the police, making it difficult to continue work. Even though food delivery was categorised as an essential service, it was difficult for them to get movement passes. This was critical for workers, because, without these passes, they could not work even when they were available, leading to loss of income. Reports of a few incidents of food delivery workers being tested positive for COVID-19 further aggravated this stigma. Food delivery workers are often seen as spreaders of virus infection.

Participant 13, a 20-year-old college student who had worked for Zomato for 15 months told us:

Customers shout and tell us to deliver and leave food at the door, even though we are supposed to make contactless delivery. We are forced to make delivery at doorsteps bearing the risk of contamination. A few days ago, a customer complained against me as I asked him to come to the gate and collect the food.

In these trying situations for food delivery workers, there is a strong incentive to hide symptoms and continue to work, as this is the only source of income for most of them. We were informed that in cases when a worker gets infected with COVID-19 his account is temporarily put on hold without any financial support.

To support food delivery workers, the food aggregators claim to have introduced medical insurance, but the terms were unclear in terms of the number of days, the insurance amount and the kind of treatment and medicine that were covered. Platforms also set up funds through crowdfunding, but again there was no clarity on the details of the fund, which raises questions about transparency. They also referred some workers to the government for financial support, suggesting that the companies want to shift responsibility to the government. This further echoes the increasing precarity for food delivery workers, exemplified by the situation of Participant 19, a secondary school educated 26-year-old who had worked for seven months with Swiggy.

After $15 \mathrm{April}^{8}$ [the end of the first lockdown period] I wanted to join the food delivery work again, but the extension of lockdown left me with no choice but to return to my home town. There is not enough saving for food and rent and there is no other may be available in near future.

\section{After the first lockdown}

During the 'unlock' period when, after 21 days of lockdown, there was some relaxation of the restrictions, food aggregators expanded their operations to essential food products. This provided some relief to the platforms and workers in terms of providing extra business, but there was no safety and compensation for these essential workers. Food delivery workers faced a precarious situation with everyday health risks, loss of income, work pressure and occupational stress. Even though the services had moved and expanded from food groceries to non-essentials, orders were still low. This forced a food delivery worker to take more orders, adding to health risk, stress and further expenses.

8 The first lockdown was of 21 days and ended on 15 April 2020. 
With the easing up of controls after the first lockdown, consumers began to return to these food platforms, but demand remained low, translating into much lower earnings for workers who were paid depending on the number of orders. Fear, psychosis and social distancing norms added further misery to this labour-intensive work. Lalvani and Seetharaman (2020) suggest that a food delivery worker is getting only 16-20 food delivery orders per day, a drop from 30-35 orders per day. Despite working for more than ten hours a day, workers were not getting the incentives they received before COVID-19. The precarity of work also increased, in a context in which platforms do not guarantee minimum pay.

The biographies of some of our interviewees illustrate the ways in which Indian food delivery workers are caught between precarious alternatives, often with a trajectory from previous employment in the informal economy.

Participant 21 was a 26-year-old with high school education, who had worked for Swiggy for almost a year. Before working as a food delivery worker, he worked in farming. But the meagre income and risky nature of farm labour forced him to migrate to the city, although his family continued to live in the village.

Participant 13 was a 23-year-old postgraduate, who had worked for Swiggy for only two months. He used to own a family shop where bangles were manufactured and sold. But the income was not enough so he joined Swiggy in order to earn extra income for the family. He wanted to learn a foreign language and migrate abroad.

In some cases, the drop in earnings from platform work was unsustainable, and workers reverted back to the traditional informal economy. This was illustrated by the narrative of Participant 8, a 26-year-old school dropout who had worked with Swiggy for six months. He described how his landlord warned him against going out for work. He realised that the meagre income he could earn in this period would not last long, so he and some of his friends rode for thousands of kilometres to Bihar. It took them over three days to reach home in dire circumstances.

\section{Collective action}

As we have seen, precarity for the food delivery workers is strongly linked to contractual work arrangements and the absence of social protection. This is aggravated by a lack of collective action. The absence of unionism is the outcome of workers' fear of losing the job - an attitude that is embedded in cultural precariousness and the ways in which insecurity and competitive culture pit one worker against another. However, the extreme increase in precariousness that has occurred since the pandemic seems to have been accompanied by a change in attitude.

Participant 16, a 28-year-old secondary school educated Swiggy worker who had been working for the platform for 18 months, described this change

All problems began with the lockdown in March. Before, this job felt good and stable but now it feels like slave work.

Nevertheless, there are still contradictions relating to the idea of platform workers as entrepreneurs, with a need for self-branding to create a distinct identity, which remains prevalent in the current labour market, particularly for workers involved in informal workspaces. This presents a serious challenge to collective action and unionisation 
efforts. The complexity of digital platforms makes collective action difficult for food delivery workers.

Nevertheless, WhatsApp has emerged as an effective instrument for the workers to communicate and organise, but there are still challenges: food delivery workers come from diverse backgrounds; this can be a strength at the workplace and important for collective bargaining but at times can be problematic.

Increasing work precarity and COVID-19 have made collectives action even more important than before. Collective action can advance the agenda of emancipation (Cant, 2019; Gyulavári, 2020). Before and during the COVID-19 pandemic the condition of informal workers led to few noted collective actions. The Indian Federation of App-based Transport Workers, which represents gig workers across the country, has been trying to reduce vulnerabilities but has found it difficult to recruit a significant membership and failed to change employers' attitudes.

However, there have been some exceptions. According to newspaper reports several trade unions raised their voice and fought for rights of food delivery workers in COVID-19 times. For example, Marathi Kamgar Sena (MKS) ${ }^{9}$ provided resilient support to a strike by delivery workers in Mumbai. Maharashtra Navnirman Kamgar Sena (MNKS) has been raising a voice for equal treatment for gig workers in Mumbai but similarly, so far with little success. Namma Chalakka Trade Union (NCTU) demanded the regulation of food aggregators for the greater welfare of gig workers in Karnataka. There have been cases of demonstrations, backed by the Centre of Indian Trade Unions (CITU) in West Bengal, Kerala, Telangana, and Andhra Pradesh. The United Food Delivery Partners' Union (UFDPU) in Bangalore supported the food delivery workers and the labour movement in demanding better working conditions in the region.

Even though unions have demanded safety and monetary support for food delivery workers in COVID-19 times there has been limited success. Despite the complexity of digital platforms and minimal support from the established unions, the food delivery workers are trying and protesting whenever they can.

The crisis has not only brought adversity but also provided an opportunity to bring about desirable changes in the economic and societal structures. This has the potential not only to improve the conditions of platform workers but also to facilitate mechanisms to counter poverty. Food delivery workers must get requisite formal recognition and protection for socio-economic wellbeing (Aneja \& Shridhar, 2019). Thus, bringing about desirable social change via legislation and affirmative actions is important.

\section{Discussion and conclusion}

Food aggregator platforms, sometimes represented as a form of disruption to traditional business models, have emerged as companies based on another form of rent-seeking. The platform economy can best be seen as a place where workers provide the means of production and technology the means of coordination, based on a contractual arrangement that passes on risks to the worker (Srnicek, 2017).

9 Marathi Kamgar Sena and Maharashtra Navnirman Kamgar Sena (MNKS) are trade unions works for welfare of gig workers in Maharashtra (India). 
As such, it can be seen as a continuation of a pattern whereby new forms of capitalism take the lead in the continuing conflict between capitalists and the working class (Coase, 1937). Even though the legal system considers both enterprise and worker as equals entering a contractual relationship, in reality the distribution of power is highly unequal.

Food delivery workers are part of a global workforce, working in all major cities, and with the potential to contribute to the emergence of a transnational movement of labour. In India, a high proportion of informal workers, such as construction workers and domestic workers, enjoy some recognition, labour union and legal protections, but food delivery workers remain invisible and ignored in public discourse.

The COVID-19 pandemic has changed this picture, capturing both public and private spaces. Along with its apparent consequences for health, it has devastated the Indian economy. This has affected all kinds of industries but largely left informal work and workers most vulnerable. It has also exposed the precarious condition of platform work, whose unprotected contractual arrangements expose them to sudden unemployment. In urban India, the impact of the Pandemic on platform-based food delivery workers has been massive, exposing the precarity in on-demand food delivery work.

Platforms term food delivery workers as 'delivery partners', and this makes the relationship between platform and delivery workers a complex one. These food delivery workers are treated as independent agents operating their own businesses and providing services on-demand. This relationship is not a traditional employer-employee one with defined responsibilities and rights. This has allowed the platform to avoid any labour welfare activity and further reduce the labour cost. For workers, this has brought a lack of employment rights, the practice of non-standard employment, and precarious working conditions, aggravating conditions for workers who are already highly vulnerable.

The COVID-19 pandemic has placed the workers in a difficult bind. With lockdown, the workers lost considerable amounts of their income, making it difficult to make ends meet. Lockdown took away their livelihood and, with little else to fall back on, they became dependent on relatives and friends, leading to severe financial distress. When they were able to work, they were exposed to health risks and associated social stigma. Consequently, they face a precarious trade-off between health risks and not being able to pay for food, rent, etc.

In the pre-COVID-19 period, there was support for the widespread argument that gig work provides autonomy and flexibility to workers, not bounded by the traditional employee-employer relationships. However, the pandemic has decisively shown that this is a luxury that is available only in times of economic stability and, even then, only for a privileged few.

It has never applied to most gig workers, especially food delivery workers for whom this work may be the only source of income. It is becoming increasingly apparent that autonomy and flexibility should not come at the cost of basic social security and protection and that the precarity of work cannot be left to be corrected by market forces. The COVID-19 has increased precarity at the workplace and should be taken as a wake-up call. This precarious situation calls for affirmative action from policymakers and platform aggregators.

(C) Sazzad Parwez and Rajiv Ranjan, 2021 


\section{REFERENCES}

Agrawal, A., J. Horton, N. Lacetera \& E. Lyons (2015). 'Digitization and the contract labour market - a research agenda', in A. Goldfarb, S. Greenstein \& C. Tucker (eds), Economic Analysis of the Digital Economy, 219-250. Accessed from www.nber.org/chapters/c12988

Alamyar, F.M. (2017). 'Future of work: Formal rights, collective action, and experiences of work within the platform economy'. Accessed from https://www.semanticscholar. org/paper/Future-of-Work\%3A-Formal-rights\%2C-collective-action-of-Alamyar/ d3efe754ab66b3500ca0da55aeafd3dd8f2clafb

Aloisi, A. (2016). 'Commoditized workers: Case study research on labour law issues arising from a set of ondemand/gig economy platforms', Comparative Labor Law \& Policy Journal, 37(3):653-691.

Aneja, U. \& A. Shridhar (2019). Worker Wellbeing on Digital Work Platforms in India, Goa: Tandem Research. Accessed from https://tandemresearch.org/assets/Worker-WellbeingTandem-Research-2019.pdf

Arntz, M., T. Gregory \& U.Z. Mannheim (2016). The Risk of Automation for Jobs in OECD Countries: A Comparative Analysis, OECD Social, Employment and Migration Working Papers, No. 189, Paris: OECD Publishing. doi: 10.1787/5jlz9h56dvq7-en

Aust, A. \& H. Holst (2006). 'From ignorance to organizing? Trade union strategies towards atypical workers in the example of call centres and temporary agency work', Industrial Beziehungen, 13, 291-313.

Benanav, A. (2019). Automation and the Future of Work, New Left Review, 5:19.

Berg, J., M. Furrer, E. Harmon \& U.R. Michael (2018). Six Silberman. Digital platforms and the future of work: Towards decent work in the online work, Geneva: International Labour Organization.

Bohle, D. \& B. Geskovits (2012). Capitalist diversity on Europe's periphery, Ithaca: Cornell University Press.

Boston Consulting Group (2020). India's online food delivery industry to touch \$8-bn mark by 2022: Report, Business Standard. Accessed from https://www.business-standard.com/ article/current-affairs/india-s-online-food-delivery-industry-to-touch-8-bn-mark-by-2022report-120012800822_1.html

Business Today (2019a). 'Swiggy plans to hire 3 lakh people in 18 months; aims to become thirdlargest employer in country', 19 October 2019.

Business Today (2019b). 'Zomato delivery boys go on strike in Mumbai, Bengaluru after food app cuts incentives', 18 September 2019.

Cant, C. (2019). Riding for Deliveroo: Resistance in the New Economy, London: Wiley, 1-180.

Cherry, M.A. \& A. Antonio (2017). Dependent contractors' in the gig economy: A comparative approach, American University Law Review, 635.

Coase, R. (1937). The nature of the firm, economica, New Series, 4 (16):386-405. Accessed from www.jstor.org/stable/2626876?seq=1\#page_scan_tab_contents

Codagnone, C. \& B. Martens (2016). 'Scoping the sharing economy: Origins, definitions, impact and regulatory issues,' SSRN Electronic Journal, 1-36. Accessed from https://papers.ssrn.com/ sol3/papers.cfm?abstract_id=2783662

De Groen, W.P. and I. Maselli (2016). The impact of the collaborative economy on the labour market. CEPS Special Report No. 138, Brussels: CEPS.

De Stefano, V. (2016). The rise of the 'just-in-time workforce': On-demand work, crowdwork, and labor protection in the 'gig-economy', Comparative Labor Law \& Policy Journal, 37(2):471-504.

Donovan, S.A., D.H. Bradley \& J.O. Shimabukuro (2016). What does the gig economy mean for workers? (CRS Report R44365). Washington, DC: Congressional Research Service. Accessed from www.fas.org/sgp/crs/misc/R44365.pdf

Dörre, K. (2005). 'Zone of Vulnerability: Insecure employment relations, precarization and trade unions', in M. Sommer, K. Dörre \& U. Schneidewind, The future was the day before yesterday: Transformation of employment relations: Insecurity instead of standard employment relations? Oldenburg: Bibliotheks und Informationssystem der Universität, 19-55. 
Drahokoupil, J. \& A. Piasna (2019). Digital labour in Central and Eastern Europe: Evidence from the etui internet and platform work Survey. ETUI Working Paper. Brussels: ETUI.

Fidler, D. (2016). Work, interrupted the new labour economics of platforms. IFTF Research Report, Palo Alto: Institute for the Future. Accessed from https://workablefutures.org/publications/ reports/work-interruptedthe-new-labor-economics-of-platforms/

Gandini A. (2019). 'Labour process theory and the gig economy', Human Relations, 72:1039-1056.

Goods, C., A. Veen, \& T. Barratt (2017). 'Being exploited and breaching your visa: the limited choices of the food delivery worker', The Conversation. Accessed from https:// theconversation.com/being-exploitedand-breaching-your-visa-the-limited-choices-of-thefood-delivery-worker-82589

Gyulavári, T. (2020). 'Collective rights of platform workers: the role of EU law', Maastricht Journal of European and Comparative Law, 27(4), 406-424.

Heeks, R. (2017). Decent work and the digital gig economy: A developing country perspective on employment impacts and standards in online outsourcing, crowdwork, etc. Development Informatics Working Paper Series No. 71, Manchester: Centre for Development Informatics Global Development Institute, SEED.

Huws, U. (2014). Labor in the global digital economy: The cybertariat comes of age, New York: NYU Press, 1-240. Accessed from http://www.jstor.org/stable/j.ctt1287j8b

Huws, U., N.H. Spencer, D.S. Syrdal \& K. Holts (2018). 'Working in the gig economy: insights from Europe', in Work in the digital age, Rowman \& Littlefield International, 153-162

Huws, U., N.H. Spencer, D.S. Syrdal \& K. Holts (2017). Work in the European gig economy: research results from the UK, Sweden, Germany, Austria, the Netherlands, Switzerland and Italy, Brussels: Foundation of European Progressive Studies and UNI Europa.

Indian Express (2020). 'Covid Impact: Over 4,400 jobs cut by 5 major Indian companies in 1 month', 27 May 2020. Accessed from https://indianexpress.com/article/business/companies/ covid-19-impact-over-4-4k-jobs-cut-by-5-major-indian-cos-in-1-month-uber-lays-off-nearly600-people-6428756/

International Labour Organization (2016). Non-standard employment around the world: Understanding challenges, shaping prospects, Geneva: International Labour Organization.

International Labour Organization (2018). The architecture of digital labour platforms: Policy recommendations on platform design for worker well-being, ILO future of work research paper series, Geneva: International Labour Organization, 6-55. Accessed from https:// www.ilo.org/wcmsp5/groups/public/---dgreports/---cabinet/documents/publication/ wcms_630603.pdf

Johnston, H. \& C. Land-Kazlauskas (2018). 'Organizing on-demand: Representation, voice, and collective bargaining in the gig economy', Conditions of Work and Employment Series, 94.

Kalleberg, A.L. (2018). Precarious lives: Job insecurity and well-being in rich democracies, Cambridge: Polity Press.

Keane, M.P. \& R. Thakur (2018). Health Care Spending and Hidden Poverty in India, UNSW Business School Research Paper No. 2018-02. doi: 10.2139/ssrn.3118615

Kenney, M. \& J. Zysman (2016). The rise of the platform economy, Issues in Science and Technology, 32(3), 61-69.

Keune, M. \& M. Pedaci (2019). Trade union strategies against precarious work: common trends and sectoral divergence in the EU. European Journal Industrial Relations, 26 (2):139-155.

Lalvani, S. \& B. Seetharaman (2020). 'The Personal and social risks that India's food delivery workers are taking during COVID-19', Wire, 12 April 2020. Accessed from https://thewire.in/ business/covid-19-food-delivery-workers.

Leighton, P. \& M. Wynn (2011). 'Classifying employment relationships: more sliding doors or a better regulatory framework?', Industrial Law Journal, 40, 5-44.

Mackenzie, E. \& A. McKinlay (2020). Hope labour and the psychic life of cultural work. Human Relations.

NASSCOM (2018). Catalyzing the ecosystem for a trillion-dollar digital economy, Hyderabad: National Association of Software and Services Companies. Accessed from https://www. nasscom.in/sites/default/files/NASSCOM-annualguidance-fy-2018.pdf 
National Sample Survey Office (2012). Informal sector and conditions of employment in India, New Delhi: NSS 66th Round, Ministry of Statistics and Programme Implementation, Government of India.

Palier, B. \& K. Thelen (2010). 'Institutionalizing dualism: complementarities and change in France and Germany', Political Sociology, 38, 119-148.

Pant, B. \& U. Shende (2020). The Impact of COVID-19 on the sharing economy in India, New Delhi: Policy Monks.

Parwez, S. (2020). 'A review of Special Economic Zone led to detrimental implications: An Indian experience', Emerging Economy Studies, 6 (2):223-239

Parwez, S. (2015). 'Modified labour welfare measure for Special Economic Zone and Implications', Indian Journal of Industrial Relations, 50(3), 386-396.

Parwez, S. (2016a). 'Labour and labour welfare in special economic zones in India with special reference to Gujarat', South Asian Survey, 23 (2):1-23.

Parwez, S. (2016b). 'A Comparative Study of Gujarat and Kerala Developmental Experiences', International Journal of Rural Management, 12 (2):104-124.

Romei, V. (2015). 'The new world of work: A changing landscape', Financial Times, 4 August 2015.

Rubery, J., Grimshaw D., Keizer A., Rubery, J., Grimshaw, D., Keizer, A. \& Johnson, M. 2018). 'Challenges and contradictions in the "normalising" of precarious work', Work, Employment and Society, 32(3), 509-527.

Salve, P. \& S. Paliath (2019). 'India's gig workers: Overworked and underpaid', Indiaspend. Accessed from https://www.indiaspend.com/indias-gig-workers-overworked-and-underpaid/

Schwander, H. (2018). 'Labour market dualization and insider-outsider divides: why this new conflict matters', Political Studies Review, 17, 14-29.

Sowmiya, A. (2020). 'As jobs vanish, salaried workers become gig economy' partners' with Swiggy, Zomato and Amazon’, Huffpost, 29 May 2020.

Srnicek N. (2017). Platform capitalism. Cambridge: Polity Press.

Stewart, A. \& J. Stanford (2017). 'Regulating work in the gig economy: What are the options?', The Economic and Labour Relations Review, 28 (3):420-437.

Stewart, P., G. Shanahan \& M. Smith (2020). Individualism and collectivism at work in an era of deindustrialisation: work narratives of food delivery couriers in the platform economy, Frontiers in Sociology, 5:49.

Sundararajan, A. (2016). The sharing economy: The end of employment and the rise of crowd-based capitalism, Cambridge: MIT Press.

The News Minute (2020). 'App-based drivers, delivery executives protest for adequate safety gear, better income', 9 June 2020.

Tiwari, S., S.G. Ram \& S. Roy (2019). 'What Is It Like to Work in a Gig Economy Job', Times of India. Available from https://timesofindia.indiatimes.com/india/what-it-is-like-to-work-in-agig-economy-job/articleshow/69371217.cms

Veen, A., T. Barratt \& C. Goods (2020). 'Platform-capital's “appetite” for control: A labour process analysis of food-delivery work in Australia', Work, Employment and Society, $34(3): 388-406$.

Will-Zocholl, M (2017). Virtual temptations: reorganising work under conditions of digitisation, virtualisation and informatisation, in K. Briken, S. Chillas, M. Krzywdzinski \& A. Marks (eds), The new digital workplace: How new technologies revolutionise work, London: Palgrave MacMillan, 62-86.

Woodcock, J. \& M. Graham (2020). The gig economy, a critical introduction, Cambridge: Polity Press. 